\title{
The involvement of osmolarity in the safety of contrast media
} CrossMark

\author{
Stefania Isola, Fabiana Furci ${ }^{*}$ and Sebastiano Gangemi
}

\begin{abstract}
Background: New non-ionic contrast agents, classified into low osmolar agents and iso-osmolar agents, present different biochemical characteristics that may influence the allergic reactions they cause. The aim of our study was to evaluate how osmolarity may affect safety in the use of contrast agents.

Case presentation: Six patients with a positive history for reaction to contrast agent were included in this study. Only one patient prick and intradermal skin test was positive. However, in 5 cases, patients presented an immediate reaction after administration of contrast agent that was not lgE mediated.

Conclusions: In this study, we focused on iodixanol, an iso-osmolar contrast agent, finding good safety of this product in patients with previous hypersensitivity reactions to contrast agent.
\end{abstract}

Keywords: Contrast media, Osmolarity, Hypersensitivity, Adverse drug reaction

\section{Background}

The use of intravenous contrast media (CM) allows the opacification of vessels and tissues while performing a radiological examination, with the purpose of providing information to evaluate a patient's clinical problem.

Iodinated CM are concentrated solutions of tri-iodinated benzene derivatives and were introduced into clinical practice in the 1950s. These medications are used for $\mathrm{X}$-ray examinations and for computed tomography (CT) [1]. Iodinated CM are classified into ionic and non-ionic types. New non-ionic CM are classified into monomeric low osmolar agents, such as iohexol, iopamidol, iopromide, ioversol, iomeprol, iobitridol and ioxilan, and dimeric iso-osmolar CM, such as iodixanol.

Cross-reactivity between iodine-based contrast agents was reported more frequently in subjects with delayed reactions than in subjects with immediate reactions [25] and seemed to depend, at least in part, on the chemical structure of the compounds [6]. A recent study [5] proposed a classification of contrast agents into subgroups based on the most frequent cross-reactivity patterns:

*Correspondence: fabianafurci@gmail.com

School and Operative Unit of Allergy and Clinical Immunology,

Department of Clinical and Experimental Medicine, University of Messina, Messina, Italy
Subgroup A

ioxitalamate, iopamidol, iodixanol,

Subgroup B iomeprol, ioversol, iohexol.

Subgroup C iobitridol, ioxaglate. amidotrizoate.

$\mathrm{CM}$ are also used for magnetic resonance imaging (MRI); the most used are gadolinium chelates or complexes $[7,8]$. These molecules are classified according to net charge, ionic or non-ionic, and structure, linear or macrocyclic.

Adverse reactions after $\mathrm{CM}$ administration have been divided into allergic and non-allergic hypersensitivity, toxic reactions (e.g. nephrotoxicity, neurotoxicity), and reactions unrelated to $\mathrm{CM}$ application [9]. The two severity scales of Ring and Messmer or Brown can be used to classify reactions [10].

Hypersensitivity reactions (HSR) are classified in immediate, if they appear within the first hour after administration, and in non-immediate, if they appear from more than $1 \mathrm{~h}$ to several days after administration [11].

While these reactions are generally mild in nature, $1 \%$ to $3 \%$ of patients exposed ionic contrast agents and $0.05 \%$ of patients exposed to non-ionic contrast agents have severe reactions and most are immediate [12]. An

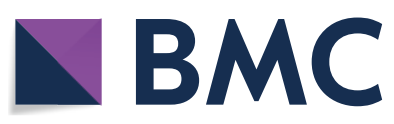

(c) The Author(s) 2018. This article is distributed under the terms of the Creative Commons Attribution 4.0 International License (http://creativecommons.org/licenses/by/4.0/), which permits unrestricted use, distribution, and reproduction in any medium, provided you give appropriate credit to the original author(s) and the source, provide a link to the Creative Commons license, and indicate if changes were made. The Creative Commons Public Domain Dedication waiver (http://creativecommons.org/ publicdomain/zero/1.0/) applies to the data made available in this article, unless otherwise stated. 
immunoglobulin E (IgE)-mediated allergic mechanism for hypersensitivity to CM can be demonstrated only in a minority of cases. Other mechanisms are involved in the pathophysiology of these reactions; in particular, for immediate cases it may be a direct membrane effect, possibly related to the osmolarity of the CM solution, with histamine release from basophils and mast cells. There are reports of high levels of tryptase in connection with severe or fatal reaction [13, 14]. Non-immediate HSRs induced by $\mathrm{CM}$ are instead $\mathrm{T}$ cell mediated [15].

The most common symptoms of immediate reactions are pruritus, urticaria, angioedema and flush. Other symptoms include dyspnoea (bronchospasm, laryngeal oedema), nausea, diarrhoea, rhinitis, hypotension, tachycardia, cardiovascular shock, cardiac arrest, respiratory arrest [14-18]. The most common symptoms of non-immediate HSRs are macular or maculopapular eruptions; other less frequent manifestations of nonimmediate HSRs may be Steven-Johnson syndrome, toxic epidermal necrolysis, acute generalized pustolosis and vasculitis $[15,19]$.

Clinical manifestations, such as heat, facial flushing and nausea, that generally occur after administration of $\mathrm{CM}$, not associated with other symptoms and which do not require medical therapy, usually resolve spontaneously and are not suggestive of allergic reactions [20].

The most frequent risk factor for an immediate HSR is a previous immediate reaction to $\mathrm{CM}$. Other risk factors for more severe immediate reactions include severe allergy, bronchial asthma, concomitant medications (e.g. ACE-inhibitors, B blockers, proton pump inhibitors), cardiac disease.

Reported predisposing risk factors for non-immediate HSRs include previous CM-induced adverse reaction, serum creatinine level $>2.0 \mathrm{mg} / \mathrm{dl}$, interleukin-2 treatment, a history of drug and contrast allergy.

Other important risk factors are: viral infections at time of CM exposure, autoimmune disease and mastocytosis [21-26].

The evaluation of patients with reactions to $\mathrm{CM}$ can be initiated during the acute phase with serum tryptase (at the onset of the reaction and 2 and $24 \mathrm{~h}$ later) [27, 28]. A twofold increase in tryptase is indicative of anaphylaxis [29].

The basophil activation test, used to detect basophil activation markers (CD45, CD18, CD63) and the lymphocyte activation test, based on the ability of T-cell to proliferate upon contact with CM in sensitized patients, are vitro methods whose sensitivity and specificity has not yet been established [30,31].

In patients with a positive history of reaction to $\mathrm{CM}$, the drug provocation test (DPT), considered the gold standard for the diagnosis of adverse drug reactions
(ADRs), plays a key role in confirming or excluding the diagnosis when there is no other available evidence and can be used to find an alternative CM. The DPT is performed by increasing doses of the $\mathrm{CM}(5,15,30$ and $50 \mathrm{cc})$ every 30-45 min for immediate HSRs, and every $60 \mathrm{~min}$ for non-immediate HSRs [2].

The current management of patients with CM hypersensitivity who need $\mathrm{CM}$ studies requires the use of non-ionic and iso-osmolar CM [32]. This approach was confirmed in our study, finding good tolerability in the use of an iso-osmolar contrast agent (iodixanol-Visipaque) available at our university hospital.

In light of evidence of reactions to $\mathrm{CM}$, which frequently occurred on first exposure, the role of osmolarity may be considered one of the most important factors to study in the choice of which alternative CM to use.

\section{Case presentations}

This study is based on analysis of data from patients with previous HSRs to CM, admitted to the Allergy and Clinical Immunology Unit of the University of Messina. The allergological investigation was performed within 6 months of the adverse reaction to CM. After an accurate medical history, according to the diagnostic procedure of the Drug Allergy Interest Group/European Network of Drug Allergy (DAIG)/(ENDA), skin tests were performed on patients who came to our observation with reaction to $\mathrm{CM}$ [3]. Clinical data were recorded using an adaptation of the ENDA drug allergy questionnaire [33].

We observed 6 patients, three with a well-documented history of iodixanol, iomeprol and iopromide HSR and three patients who showed a reaction to unspecified CM. The patients came to our observation due to an adverse reaction to a $\mathrm{CM}$ and the need to perform a radiological examination with contrast agent; it was not possible to carry out an alternative radiological examination and hence, an alternative CM needed to be identified. None of the patients who came to our evaluation had allergicrelevant comorbidities, i.e. active urticaria, symptomatic bronchial asthma, recurrent angioedema, mastocytosis, idiopathic anaphylaxis.

We performed skin prick tests (SPT) and intradermal tests (IDT) on the volar forearm and we read them after $20 \mathrm{~min}$ and on days 2 and 3 . We have reported as positive a SPT if there was a wheal of $\geq 3 \mathrm{~mm}$ in diameter after $20 \mathrm{~min}$ (immediate reading) or if an erythematous induration occurred at the skin test site on days 2 or 3 (delayed reading). We injected IDT solution (0.03$0.05 \mathrm{ml}$ ) into the skin to produce a bleb of $4-5 \mathrm{~mm}$ in diameter. The IDT was interpreted as positive if the size of the initial wheal had increased by at least $3 \mathrm{~mm}$ in diameter and was surrounded by erythema after $20 \mathrm{~min}$ 
(immediate) or if an erythematous induration at the skin test site was present in the delayed readings. We used histamine $(0.01 \%)$ and saline $(0.9 \%)$ as positive and negative controls, respectively. The patients, under hospital surveillance, completed the test with intravenously administration during the next radiological examination starting with a graded dose of the CM taking as a model a study by Soffer et al. [32]. Patients were given $1 \%$ of the total expected dose $1 \mathrm{~h}$ before radiological procedure and were monitored for $30 \mathrm{~min}$. They then received 10\% of the total expected dose, with monitoring for another $30 \mathrm{~min}$. They received the final dose during the radiological examination. This careful monitoring proved to be of considerable importance since previous studies revealed that skin tests do not always predict a CM hypersensitivity reaction [3].

\section{Case 1}

A female patient, 75, was sent to our unit for observation from the general gastrointestinal surgery unit. The patient had a positive history of antibiotic allergy, and a CM (iodixanol) reaction (skin erythema) during coronary angiography, 2 months previous. The cutaneous manifestation occurred after 20 min from administration of the contrast agent, with maintenance of vital parameters. Therefore, the patient was treated with chlorpheniramine $10 \mathrm{mg}$ intramuscular vial plus hydrocortisone $200 \mathrm{mg}$, intravenously. The cutaneous manifestation disappeared $6 \mathrm{~h}$ after therapy.

The clinical history of this patient was silent for inhalants, food allergy and latex allergy. Given that the patient had now to undergo a CT angiography, a challenge test for iodixanol was therefore suggested.

SPTs and IDTs were performed with iodixanol according to the following scheme of administration: SPT 1:10 diluted, SPT undiluted, IDT 1:1000 diluted, IDT 1:100 diluted, IDT 1:10 diluted. The test result was negative. The patient also subsequently tolerated the radiological examination performed using the CM tested, well.

\section{Case 2}

A male patient, 65 , suffering from arteriovenous malformation, was sent from the neurosurgery unit as a predetermined adverse reaction (erythematous skin reaction) to an unknown CM had been reported, with normal vital parameters, 3 months previously. The erythematous skin reaction occurred 15 min after administration of the CM: the reaction was resolved $2 \mathrm{~h}$ after cortisone and antihistamine therapy, as practiced in case 1 .

The patient had a negative history for latex allergy, respiratory allergies, and food allergy.

SPTs and IDTs were therefore performed for iodixanol as in case 1 . The test result was negative. The patient also subsequently tolerated the radiological examination performed using the CM tested, well.

\section{Case 3}

A male patient was sent for observation from the hepatology unit with a history of erythema and itching which had appeared immediately, 10 min after administration of an iodinated unspecified CM, 6 weeks previously. The patient did not present impairment of vital parameters. Resolution of skin signs and pruritic symptoms occurred $2 \mathrm{~h}$ after cortisone and antihistamine therapy, as practiced in case 1 .

He had a negative history for latex allergy, respiratory allergies, and food allergy.

As the patient had now to undergo an abdominal CT with CM, SPTs and IDTs were performed for iodixanol, as in case 1 . The test result was negative. Subsequently, the CM used was well tolerated during the execution of the radiological examination.

\section{Case 4}

A male patient, 57, was sent for observation from the neuroendocrinology unit with a reported adverse reaction to an unspecified CM, with appearance of urticaria $20 \mathrm{~min}$ after administration of the contrast agent, without compromising vital parameters. The cutaneous manifestation disappeared $5 \mathrm{~h}$ after cortisone and antihistamine therapy as practiced in case 1 .

The patient had a positive history for allergic rhinitis, and a negative history for food allergy and latex allergy.

SPTs and IDTs were therefore performed for iodixanol as in case 1 . The test result was negative. The CM used was well tolerated during the execution of the radiological examination.

\section{Case 5}

A female patient, 67, was referred to us for an allergological evaluation. The patient was undergoing chemotherapy with bevacizumab for ovarian carcinoma, and it was reported that she had presented two episodes of adverse reaction to iomeprol used for the execution of CT examinations.

In both episodes, the patient presented skin erythema, pruritus, facial edema with accentuation of symptomatology and cutaneous manifestations during the second episode, before which she had been pre-medicated with Prednisone $50 \mathrm{mg}$ by mouth at $13 \mathrm{~h}, 7 \mathrm{~h}$ and $1 \mathrm{~h}$ before $\mathrm{CM}$ injection, plus chlorpheniramine $10 \mathrm{mg}$ intramuscular $1 \mathrm{~h}$ before CM $[34,35]$. These manifestations, which did not compromise vital parameters, appeared within $10 \mathrm{~min}$ of administration of the contrast agent and regressed within $12 \mathrm{~h}$ from the cortisone and antihistamine therapy practiced as in case 1 ; in 
addition, methylprednisolone $40 \mathrm{mg}$ was administered intravenously.

The patient had a negative history for latex allergy, respiratory allergies, and food allergy.

SPTs and IDTs for iomeprol were performed as in case 1 , and the test result was positive. Subsequently, we chose to perform SPTs and IDTs for iodixanol, with negative result. The CM tested was administered and well tolerated during the subsequent radiological examination.

\section{Case 6}

A 67-year-old female patient came to our observation with a history of adverse contrast reaction: 10 years previous, after administration of unspecified CM for abdominal CT, the patient had presented skin rash and swelling of the limb, the injection site of the CM, with maintenance of vital parameters.

A month previous, during angio-CT, 15 min after injection of the CM, iopromide, despite having been premedicated as in case 5, the patient presented erythema and mild edema of the limb in the injection site of the CM and dry cough which lasted for some days. Immediately upon the appearance of the adverse reaction the patient was treated with chlorpheniramine $10 \mathrm{mg}$ intramuscular therapy. In addition to the aforementioned therapy, salbutamol was administered by aerosol. Blood pressure, oxygen saturation and thoracic objectivity were normal.

The patient had a negative history for latex allergy, respiratory allergies, and food allergy. Given the need to repeat angio-CT due to the presence of cerebral aneurysms, SPTs and IDTs were therefore performed with iopromide according to the following scheme of administration: SPT 1:10 diluted, SPT undiluted, IDT 1:1000 diluted, IDT 1:100 diluted, IDT 1:10 diluted. The test results were negative. Subsequently, the CM used was well tolerated during the execution of the radiological examination.

\section{Discussion and conclusions}

In our study, skin tests have proved useful for the confirmation of CM allergy and for identifying a safe alternative product for $\mathrm{CM}$ re-exposure. A positive skin test result was found only in one patient, case 5. Subsequently, in this patient iodixanol presented negative result. Crossreactivity between iomeprol and iodixanol, belonging to the same subgroup but with different osmolarity, was not found. Five patients presented negative skin test results for iodixanol, one patient for iopromide (case 6). All patients, subsequently, tolerated CM tested during radiological examination.

The decreased movement of extracellular fluid osmotically, as well as efflux of the CM may explain the higher tolerability of an iso-osmolar agent, such as iodixanol
(Visipaque) [35]. Indeed, Sutton et al. [36] reported that iodixanol is well tolerated in the early phase of injection, constituting a safer $\mathrm{CM}$ in relation to immediate HSR. In addition, Gomi et al. [37] reported immediate HSR in $2.7 \%$ of patients with iodixanol in comparison to $3.5 \%$ with iopromide. Therefore, in agreement with other authors according to our findings, iodixanol presents better compliance and safety for patients with a positive history for immediate HSR [35].

As noted in case 5 , there is no certainty regarding the effectiveness of premedication therapy in preventing a possible adverse reaction $[34,38]$.

This result leads us to hypothesize how osmolarity of the contrast agent is one of the main factors that affects the release of cell mediators and, therefore, the appearance of an adverse reaction. Thus, the osmolarity of a contrast agent may be considered an important factor to be taken into account in those patients who present an immediate reaction to $\mathrm{CM}$ and with negative SPTs and IDTs for that particular CM.

Indeed, the importance of drug osmolarity can also be understood from the general medical indications regarding treatment of anaphylaxis, according to which, rapid intravenous administration of isotonic saline is recommended, avoiding, instead, plasma expanders due to the risk of mast cell degranulation [39]. Fluid and oxygen are the most ubiquitous therapeutic interventions in a patient in critical health conditions. The therapeutic administration of fluids aims to expand intravascular, interstitial and intracellular compartments and, in literature, anaphylactoid reactions have been reported with all classes of colloids. These anaphylactoid reactions have an incidence of $0.07 \%-0.15 \%$, but often such reactions are not reported and therefore misunderstood [40, 41]. Since crystalloid and colloid fluids present different adverse effects, including nephrotoxicity, anticoagulation, acid base disturbance and anaphylactoid reactions, it is important to choose the type of fluid to be administered based on the characteristics of the different types of fluids, their potential effects following administration and the physiologic needs of patients [42].

Thus, with this paper, we would like to further reflect on how a complete evaluation of an individual's allergic susceptibility and of the biochemical and osmolar characteristics of CM may be of help in choosing the correct $\mathrm{CM}$ hypersensitivity management strategy.

More studies are needed to investigate the underlying mechanism of osmolarity in patients with immediate HSR and negative skin tests result.

\section{Abbreviations}

CM: contrast media; CT: computed tomography; MRI: magnetic resonance imaging; HSR: hypersensitivity reaction; DPT: drug provocation test; ADR: 
adverse drug reaction; DAIG/ENDA: Drug Allergy Interest Group/European Network of Drug Allergy; SPT: skin prick test; IDT: intradermal test.

\section{Authors' contributions}

All the signing authors equally contributed in the clinical work, collected the data and drafted the manuscript. All authors read and approved the final manuscript.

\section{Acknowledgements}

We would like to thank Prof. Marcello Longo, Neuroradiology Unit Policlinic of Messina, for the description of the methodological part referring to the challenge test carried out in the Department of Biomedical Sciences and Morphological and Functional Imaging, University of Messina, Messina, Italy.

\section{Competing interests}

The authors declare that they have no competing interests.

\section{Availability of data}

Data supporting our findings is stored on a database in the Allergy and Clinical Immunology Unit, Department of Clinical and Experimental Medicine, University of Messina, Messina, Italy.

\section{Consent for publication}

Written consent for publication was obtained from all patients.

\section{Ethics approval and consent to participate}

Informed consent was obtained from patients before performing prick and intradermal skin tests in ambulatory settings. Ethics approval was not required as diagnostic tests were carried out during routine outpatient activity.

\section{Funding}

This study was supported by SIAAIC (Grant No. TC01621483)

\section{Publisher's Note}

Springer Nature remains neutral with regard to jurisdictional claims in published maps and institutional affiliations.

Received: 21 March 2018 Accepted: 24 August 2018 Published online: 03 September 2018

\section{References}

1. Kvedarine V, Martins P, Rouanet L, Demoly P. Diagnosis of iodinated contrast media hypersensitivity: results of a 6 -year period. Clin Exp Allergy. 2006:36:1072-7.

2. Rosado Ingelmo A, Doña Diaz I, Cabañas Moreno R, Moya Quesada MC, García-Avilés C, García Nuñez I, et al. Clinical practice guidelines for diagnosis and management of hypersensitivity reactions to contrast media. J Investig Allergol Clin Immunol. 2016;26:144-55.

3. Brockow K, Romano A, Aberer W, Bircher AJ, Barbaud A, Bonadonna P, et al. Skin testing in patients with hypersensitivity reactions to iodinated contrast media—a European multicenter study. Allergy. 2009;64:234-41.

4. Torres MJ, Gomez F, Doña I, Rosado A, Mayorga C, Garcia I, et al. Diagnostic evaluation of patients with nonimmediate cutaneous hypersensitivity reactions to iodinated contrast media. Allergy. 2012;67:929-35.

5. Lerondeau B, Trechot P, Waton J, Poreaux C, Luc A, Schmutz JL, et al. Analysis of cross-reactivity among radiocontrast media in 97 hypersensitivity reactions. J Allergy Clin Immunol. 2016;137:633-5.

6. Seitz CS, Pfeuffer P, Raith P, Bröcker EB, Trautmann A. Radiocontrast mediaassociated exanthema: identification of cross-reactivity and tolerability by allergologic testing. Eur J Radiol. 2009;72:167-71.

7. Dillman JR, Ellis JH, Cohan RH, Strouse PJ, Jan SC. Frequency and severity of acute allergic-like reactions to gadolinium containing i.v. contrast media in children and adults. AJR Am J Roentgenol. 2007;189:1533-8.

8. Jung JW, Kang HR, Kim MH, Lee W, Min KU, Han MH, et al. Immediate hypersensitivity reaction to gadolinium-based MR contrast media. Radiology. 2012;264:414-22.
9. Feltrin GP, Zandonà M, Rettore C, Miotto D. Fondamenti sui mezzi di contrasto iodati e reazioni avverse. Radiol Med. 2004;107:8-31.

10. Brown SG. Clinical features and severity grading of anaphylaxis. J Allergy Clin Immunol. 2004;114:371-6.

11. Brockow K, Ring J. Classification and pathophysiology of radiocontrast media hypersensitivity. Chem Immunol Allergy. 2010;95:157-69.

12. Wolf GL, Mishkin MM, Roux SG, Ef Halpem, Gottlieb J, Zimmerman J, et al. Comparison of the rates of adverse drug reactions: ionic contrast agents, ionic agents combined with steroids, and nonionic agents. Invest Radiol. 1991;26:404-10.

13. Laroche D, Aimone-Gastin I, Dubois F, Huet H, Gèrard P, Vergnaud MC, et al. Mechanisms of severe, immediate reactions to iodinated contrast material. Radiology. 1998;209:183-90.

14. Brockow K, Vieluf D, Puschel K, Grosch J, Ring J. Increased postmortem serum mast cell tryptase in a fatal anaphylactoid reaction to nonionic radiocontrast medium. J Allergy Clin Immunol. 1999;104:237-8.

15. Gomez E, Ariza A, Blanca-Lopez N, Torres MJ. Nonimmediate hypersensitivity reactions to iodinated contrast media. Curr Opin Allergy Clin Immunol. 2013;13:345-53.

16. Katayama H, Yamaguchi K, Kozuka T, Takashima T, Seez P, Matsuura K. Adverse reactions to ionic and nonionic contrast media. A report from the Japanese committee on the safety of contrast media. Radiology. 1990;175:621-8.

17. Kalimo K, Jansen CT, Kormano M. Allergological risk factors as predictors of radiographic contrast media hypersensitivity. Ann Allergy. 1980;45:253-5.

18. Brockow K. Immediate and delayed cutaneous reactions to radiocontrast media. Chem Immunol Allergy. 2012;97:180-90.

19. Brockow K, Christiansen C, Kanny G, Clément O, Barbaud A, Bircher A, et al. Management of hypersensitivity reactions to iodinated contrast media. Allergy. 2005;60:150-8.

20. Trcka J, Schmidt C, Seitz CS, Brocker EB, Gross GE, Trautmann A. Anaphylaxis to iodinated contrast material: nonallergic hypersensitivity or IgE-mediated allergy? AJR Am J Roentgenol. 2008;190:666-70.

21. Bettmann MA, Heeren T, Greenfield A, Goudey C. Adverse events with radiographic contrast agents: results of the SCVIR contrast agent registry. Radiology. 1997;203:611-20.

22. Ansell G, Tweedie MC, West CR, Evans P, Couch L. The current status of reactions to intravenous contrast media. Invest Radiol. 1980;15:32-9.

23. Choyke PL, Miller DL, Lotze MT, Whiteis JM, Ebbitt B, Rosenberg SA. Delayed reactions to contrast media after interleukin-2 immunotherapy. Radiology. 1992;183:111-4.

24. Kobayashi D, Takahashi O, Ueda T, Arioka H, Akaishi Y, Fukui T. Asthma severity is a risk factor for acute hypersensitivity reactions to contrast agents: a large-scale cohort study. Chest. 2012;141:1367-8.

25. Pichler WJ, Yawalkar N, Britschgi M, Depta J, Strasser I, Schmid S, Kuechler $\mathrm{P}$, et al. Cellular and molecular pathophysiology of cutaneous drug reactions. Am J Clin Dermatol. 2002;3:229-38.

26. Ramírez E, Tong HY, Fiandor A, Martín-Hervás C, Rivero D, Oñate M, et al. Hypersensitivity reactions to contrast media injections: a nested casecontrol study. Ann Allergy Asthma Immunol. 2014;113:488-9.

27. Fernandez J, Blanca M, Moreno F, Garcia J, Segurado E, del Cano A, et al. Role of tryptase, eosinophil cationic protein and histamine in immediate allergic reactions to drugs. Int Arch Allergy Immunol. 1995;107:160-2.

28. Gomez E, Torres MJ, Mayorga C, Blanca M. Immunologic evaluation of drug allergy. Allergy Asthma Immunol Res. 2012;4:251-63.

29. Cardona Dahl V, Cabañes Higuero N, Montserrat Fernández Rivas M, Freijó Martín C, Guardia Martínez P, de la Hoz Caballer B, et al. Grupo de trabajo de la Guía GALAXIA de actuación en anafilaxia. [Guideline for the management of anaphylaxis]. Med Clin (Barc). 2011;136:349-55.

30. Pinnobphun P, Buranapraditkun S, Kampitak T, Hirankarn N, Klaewsongkram J. The diagnostic value of basophil activation test in patients with an immediate hypersensitivity reaction to radiocontrast media. Ann Allergy Asthma Immunol. 2011;106:387-93.

31. Torres MJ. Basophil activation test (BAT) in the diagnosis of immediate hypersensitivity reactions to radiocontrast media-reply. Allergy. 2013;68:1628-9.

32. Soffer G, Cohen B, Toh J, Edelman D, Garg K, Jariwala S. Successful graded dose challenge to iodixanol radiocontrast media in a patient with delayed anaphylaxis to iohexol. Vasc Endovasc Surg. 2018;52:59-60 
33. Demoly P, Kropf R, Bircher A, Pichler WJ. Drug hypersensitivity: questionnaire. Allergy. 1999;54:999-1003.

34. Yocum MW, Heller AM, Abels RI. Efficacy of intravenous pretesting and antihistamine prophylaxis in radiocontrast media-sensitive patients. J Allergy Clin Immunol. 1978;62:309-13.

35. Gharekhanloo F, Torabian S. Comparison of allergic adverse effects and contrast enhancement between iodixanol and iopromide. Iran J Radiol. 2012;9:63-6.

36. Sutton A, Finn P, Campbell P, Price D, Hall J, Stewart M, et al. Early and late reactions following the use of iopamidol 340, iomeprol 350 and iodixanol 320 in cardiac catheterization. J Invasive Cardiol. 2003;15:133-8.

37. Gomi T, Nagamoto M, Hasegawa M, Katoh A, Sugiyama M, Murata $\mathrm{N}$, et al. Are there any differences in acute adverse reactions among five low-osmolar non-ionic iodinated contrast media? Eur J Radiol. 2010;20:1631-5.

38. Worthley DL, Gillis D, Kette F, Smith W. Radiocontrast anaphylaxis with failure of premedication. Intern Med J. 2005;35:58-60.

39. Lieberman PL. Recognition and first-line tratment of anaphylaxis. Am J Med. 2014;127:S6-11.

40. Ventura Spagnolo E, Calapai G, Minciullo PL, Mannucci C, Asmundo A, Gangemi S. Lethal anaphylactic reaction to intravenous gelatin in the course of surgery. Am J Ther. 2016:23:1344-6.

41. Fisher MM, Brady PW. Adverse reactions to plasma volume expanders. Drug Saf. 1990;5:86-93.

42. Varrier M, Ostermann M. Fluid composition and clinical effects. Crit Care Clin. 2015:31:823-37.
Ready to submit your research? Choose BMC and benefit from:

- fast, convenient online submission

- thorough peer review by experienced researchers in your field

- rapid publication on acceptance

- support for research data, including large and complex data types

- gold Open Access which fosters wider collaboration and increased citations

- maximum visibility for your research: over $100 \mathrm{M}$ website views per year

At BMC, research is always in progress.

Learn more biomedcentral.com/submissions 